\title{
Experimental Study on Seismic Performance in Beam- Column Joint Using Hybrid Fibers
}

\author{
Ganesh Kumar.D \\ Mepco Schlenk Engineering College, Sivakasi- \\ 626005 , \\ Tamilnadu, India
}

\author{
Dr. S.Prabavathy \\ Mepco Schlenk Engineering College, Sivakasi- \\ 626005, \\ Tamilnadu, India
}

\begin{abstract}
An experimental investigation was carried out to study the effect of hybrid fibers on the strength and behavior of High performance concrete beam column joints subjected to cyclic load. A total of 12 reinforced concrete beams column joints were casted and tested. Design mix of M25 is chosen which is widely used in residential. Crimped steel fibers and Glass fibers were used in hybrid form. From cube tests, the volume fraction of (i) crimped steel fibers $0.75 \%$ (ii) glass fibers viz. $0.33 \%$ gives best results. Addition of fibers in hybrid form improved many of the engineering properties such as the crack pattern, ultimate load and ductility factor of the composite. The combination of $0.75 \%$ volume fraction of steel fibers and $0.33 \%$ volume fraction of Glass fibers gave better performance with respect to energy dissipation capacity and stiffness degradation than the other combinations. This project proposed that beam column joint is the weak zone where failure occurs and crack pattern is linear form. To resist the cracks, different types of fibers in linear form are introduced in the joint and also to improve the ductility property in the weak zone of the Beam-Column joint.
\end{abstract}

Keywords: energy dissipation, stiffness degradation, hybrid fibers, beam-column joint, ductility factor

\section{INTRODUCTION}

Concrete made from ordinary Portland cement is strong in compression but weak in tension and tends to be brittle. Recent Earthquakes Failures majorly happen by improper design of reinforced concrete structures with low ductility .This study is to increase Strength and ductility of structures depend mainly on proper detailing in beam column joints. The forces acting at the junction interrupt the shear strength of the member. Seismic force is a type of force in which horizontal and vertical forces whose magnitudes are very much higher in the adjacent beam columns. Ordinary Portland cement loses its tensile resistance after the formation of multiple cracks at the zone. To resist these types of cracks and to improve the strength and to make the structure more ductile in nature Hybrid mix of Fibers are added to resist Tensile resistance of cyclic loading. Beam column joint is the crucial zone in structural component. To transfers the loads from beam to column adequate stiffness and strength is provided. Formation of Plastic hinge is prevented in column which makes the entire structure collapse within fraction of time. To make the Beam column joint more ductile in nature closed hoop stirrups are provided in Transverse reinforcement for the entire Development length Reinforcing Bars was recommended in IS 13920:1993 with maximum of $150 \mathrm{~mm}$ spacing. Diagonal reinforcement is provided in joint zone which transfer the compression loads to tensile zone.

This Study aims to provide information on the properties and applications of the more commonly available fibers and their uses to produce concrete with certain characteristics. A fiber is a small reinforcing material produced from various materials like steel, glass. A numerical parameter describing a fiber as its aspect ratio is defined as the fiber length, divided by fiber diameter $[1 / \mathrm{d}]$. Typical aspect ratio $[1 / \mathrm{d}]$ range from 30 to 150 . Fibers of diameters are 0.25 to $0.76 \mathrm{~mm}$ for steel and 0.02 to $0.5 \mathrm{~mm}$ for other fibers. In this Study selection of Steel fiber of aspect ratio 60 and Glass fiber of aspect Ratio 100 is chosen. The plain concrete fails suddenly when the deflection corresponding to the ultimate flexural strength is increased, on the other hand fiber-reinforced concrete continue to sustain considerable loads even at deflections considerably in excess of the fracture deflection of the plain concrete.

N.Ganesan et. al has carried out an experimental programme to compare the behavior of high performance concrete (HPC) and steel fiber reinforced concrete (SFRHPC) beam -Column joints under cyclic loading. Liu, Cong et. al has investigated the seismic behaviour and failure modes of beam-column joint sub-assemblies reinforced with steel fibers to compare the performance of steel fiber reinforced Beam - Column joints were compared with that of conventional joints. Tang Jiuru et. al has studied about the behavior of beam-column joints that employ steel-fiber reinforced concrete (SFRC), under reversed cyclic loading. K.R.Bindhu et. al has investigated the effect of cross-inclined bars at the joint as confining reinforcement on the behaviour of exterior reinforced concrete beam-column connections subjected to earthquake loading.

\section{RESEARCH SIGNIFICANCE}

Reinforcement detailing is very difficult in the Beam-column Joint because of providing transverse reinforcement is getting congested compaction is not possible at that zones. This study is to increase tensile resistance of the exterior beam-column joints and to increase the strength of the joints.it is possible to achieve the high ductile behavior in the beam column joints by providing hybrid combination mix of steel and glass fibers. By providing hybrid fibers at these joints, it reduces the transverse reinforcement and prevents the congestion in reinforcement at the joints.

\section{EXPERIMENTAL PROGRAMME}

\subsection{Materials}

\subsubsection{Steel Fiber reinforced concrete}

Steel fiber reinforced concrete is a composite material which is made up from cement concrete mix and steel fibers as a reinforcing. The steel fibers, which are uniformly distributed in the cementations mix . This mix, have various volume fractions, geometries, orientations and material properties. It has been shown in the research that fibers with low volume 
fractions $(<1 \%)$, in fiber reinforced concrete, have an insignificant effect on both the compressive and tensile strength.

Steel Fiber of size (30mm with 0.5 Diameter) which have a Aspect ratio of 60.

Generally SFRC is very ductile and particularly well suited for structures which are required to exhibit:-

- High fatigue strength resistance to impact, blast and shock loads

- Shrinkage control of concrete

- Tensile strength, very high flexural, shear

- Erosion and abrasion resistance to splitting

- Temperature resistance, high thermal

- Earth quake resistance

The degree of improvement gained in any specific property exhibited by SFRC is dependent on a number of factors that include:-

Concrete mix and its age

- Steel fiber content, volume fraction

- Fiber geometry, its aspect ratio (length to diameter ratio) and bond characteristics volume fraction.

\subsubsection{Glass Fiber reinforced concrete}

Glass fiber-reinforced concrete is (GFRC) basically a concrete composition which is composed of material like cement, sand, water, and admixtures, in which short length discrete glass fibers are dispersed. Glass Fiber of size $(50 \mathrm{~mm}$ with 0.2 Diameter) which have an aspect ratio of 100 . Including fibers in the concrete can improve the tensile strength and impact strength of the material. GFRC has been used for a period of 30 years in several construction elements but at that time it was not so popular, mainly in non-structural ones, like facing panels (about 80\% of the GRC production), used in piping for sanitation network systems, decorative nonrecoverable formwork, and other products. At the beginning age of the GFRC development, one of the most considerable problems was the durability of the glass fiber, which becomes more brittle with time, due to the alkalinity of the cement mortar. After some research, significant improvement have been made, and presently, the problem is practically solved with the new types of alkali-resistant (AR resistance) glass fibers and with mortar additives that prevent the processes that lead to the embrittlement of GFRC.

\subsection{Mix Proportion}

Normal Concrete Design of M25 is chosen with reference to IS 13920 which is normally used for Residential buildings. The Code prefers a Minimum grade of M20. Workability of the Concrete mix is kept constant at the compaction factor of 0.9.Mix proportions were maintained constant for all the mixes. However the Steel and Glass Fibers were added to the reinforced concrete to increase the tensile resistance in the beam column joint.

\section{Table 1 Mix Proportions $\left(\mathrm{kg} / \mathrm{m}^{3}\right)$}

\begin{tabular}{|c|c|c|c|}
\hline Cement & Fine Aggregate & Coarse Aggregate & Water \\
\hline 412 & 419.25 & 1349 & 0.43 \\
\hline
\end{tabular}

\subsection{Specimen Details}

In this paper, twelve exterior beam column joints were cast and tested under cyclic loading. The dimensions and details of the reinforcement of the beam column joints are given in Figure 1. The column was reinforced with four numbers of 12 $\mathrm{mm}$ diameter high yield strength deformed (HYSD) bars, and the beam was provided with $12 \mathrm{~mm}$ diameter HYSD bars at the top and bottom to entire length of the Beam. HYSD bars of $6 \mathrm{~mm}$ diameter were used as ties in columns and stirrups in the beams. Different Mix proportions of Steel Fibers of 0.25, $0.50,0.75$ and 1.00 and glass Fibers of $0.33,0.67$ and 1 is mixed along with all the proportions with steel and glass together into a hybrid form. From the results obtained from the different volume fractions of Fibers, Steel of $0.75 \%$ and glass of $0.33 \%$ gives the best values in both compression and tension.

Experimental study of casting and testing of 12numbers of exterior beam column joints tested with reverse cyclic loading. Mix proportions of crimped steel fibers $0.75 \%$ (58. $\mathrm{kg} / \mathrm{m} 3)$ and glass fibers of $0.33 \%(24.2 \mathrm{~kg} / \mathrm{m} 3)$. The Cross sections of Beam-column joint is $150 \times 200 \mathrm{~mm}$. Column is Reinforced with Four numbers of $12 \mathrm{~mm}$ diameter, and $10 \mathrm{~mm}$ diameter of diagonal reinforcement with development length of $280 \mathrm{~mm}$ from both the joints along top and bottom directions in column. Beam is reinforced with 2 Nos of $12 \mathrm{~mm}$ diameter of HYSD bars at top and bottom. $6 \mathrm{~mm}$ diameter bar is used as ties in columns and stirrups in beams. The dimensions and detailed reinforcement is shown in figure 1.

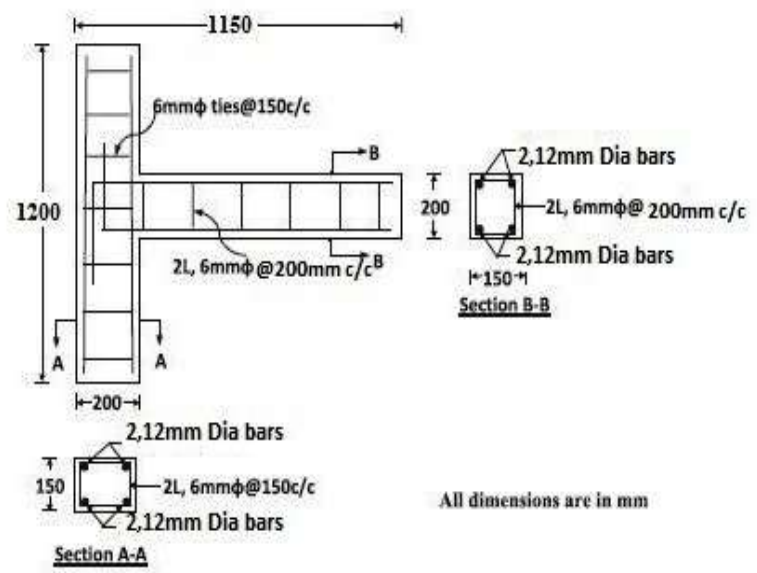

Figure 1 Details of Reinforcement

\subsection{Testing}

The Test Frame Setup of 20tonnes is arranged in order to apply cyclic load on the exterior beam column joint as Cantilever action. Specimens were testes after 28days of curing. Column is arrested at both top and bottom to provide lateral movements while applying loads. Top portion of column is arrested like hinges support by use of Load cell, bottom portion is arrested by steel casing arranged for the specimen size.

Axial Compressive load of $20 \%$ of axial capacity of the column is applied over the column to make stable. Beam is loaded with reverse cyclic loading through $200 \mathrm{kN}$ hydraulic jack connected to loading was increased; the loading was continued till the failure obtains at the joint. For every intervals of loading, the deflection at the beam is noted down by use of dial gauge having a least count of $0.01 \mathrm{~mm}$ and $50 \mathrm{~mm}$ travel. 


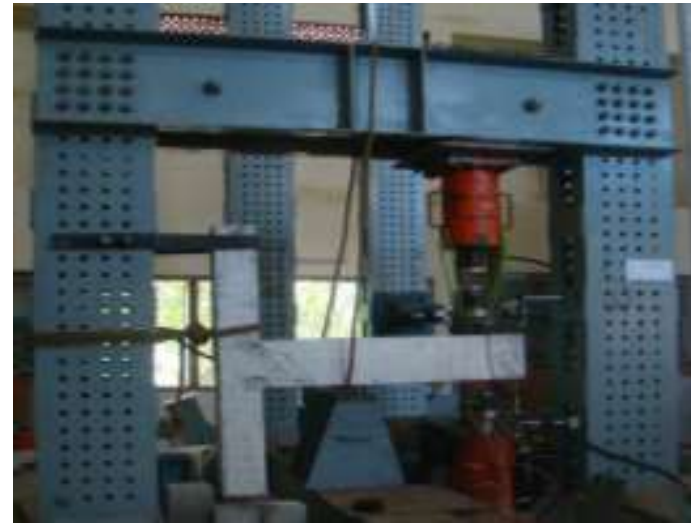

Figure 2 Experimental Test Setup

\subsection{Behavior of the specimens:}

The failure is first observed in beam column junction. Continuous increasing in load additional cracks on beam portion and propagation of some of the initial cracks. Failure of the cracks widened leading to the failure of the joint. Most of the cracks developed at the beam near the column. Hybrid mix concretes have more number of finer cracks was formed the hybrid combination of glass and steel fiber is used to control the cracks both micro and macro level. Glass fiber arrest the macro cracks and it control the formation of macro cracks, Steel fiber plays a role in restrict the widening of macro cracks and increase the energy absorption capacity of the member.

\subsection{Finite Element Analysis using Abaqus}

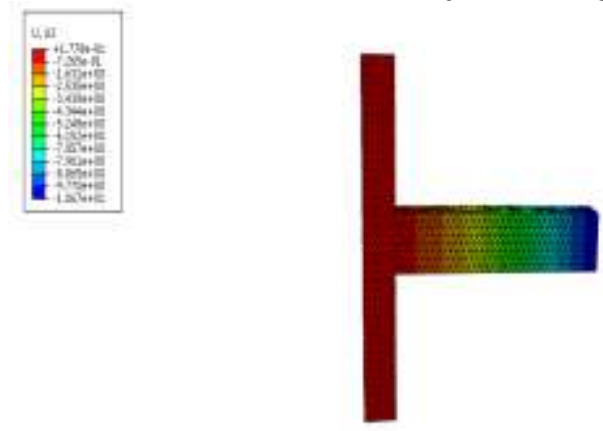

\section{i}

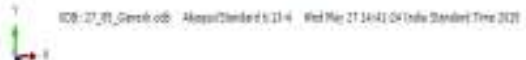

Figure 3 Plotting of Deflection contour in specimen
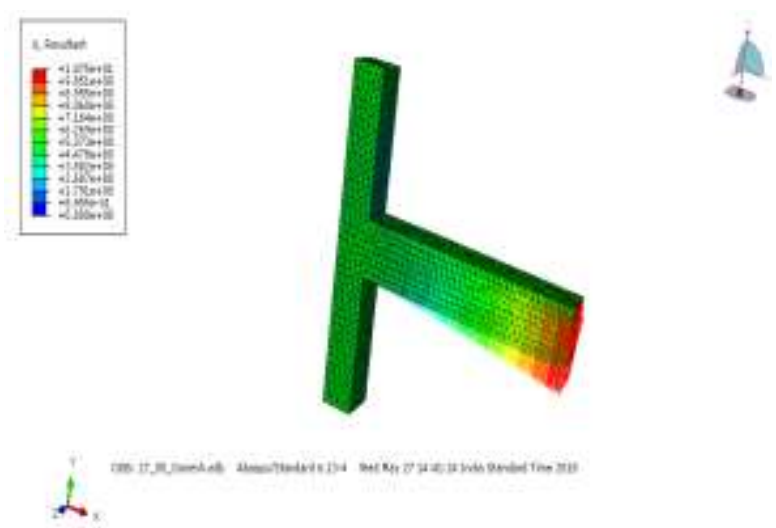

Figure 4 Resultant deflection (deformed+undeformed Shape)

\section{RESULTS AND DISCUSSION}

\subsection{Load-Deflection behavior}

It shows the typical load deflection plots of HFRC specimen tested under reversed cyclic loading. The load-deflection obtained for the joints was similar to that obtained for steel fiber reinforced concrete. The load deflection is drawn in graph for graphical representation by use of the load applied to the specimen to its deflection value. Using these envelopes the first crack load, energy absorption capacity and ductility factor for the specimens were obtained and listed. It can be observed from Fig. that in HFRC, the ultimate load and the corresponding deflection of specimens were increased as the hybrid fibre content increases. This could be attributed to the ability of these fibres in arresting the micro cracks as well as macro cracks. As and when micro cracks develop in the matrix, the glass fibres in the vicinity of such micro cracks will try to arrest these cracks and prevent further propagation. After the formation of cracks steel fibres intercept them and the bridging action of fibres reduces the widening of cracks. Also the cracks have to take a meandering path due to the interception of fibres which results in the demand of more energy for further propagation of cracks; this in turn increases the ultimate load. However, at higher percentages of glass fibre content, in fact, a reduction in strength has been found.

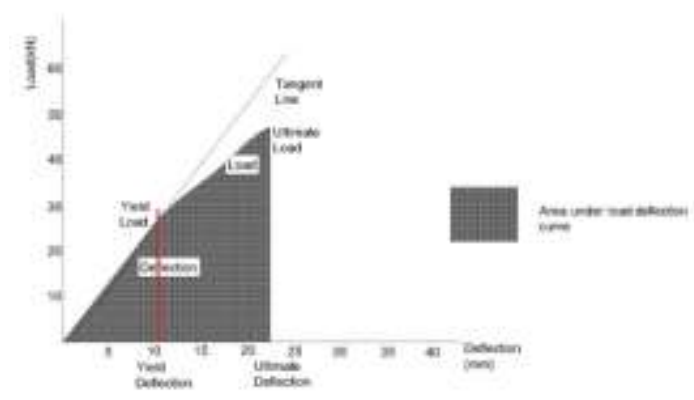

Figure 5 Energy Absorption Graph

Table 2 Energy Absorption

\begin{tabular}{|c|c|c|c|}
\hline $\begin{array}{c}\text { Designation } \\
\text { of the } \\
\text { Specimen }\end{array}$ & $\begin{array}{c}\text { Area } \\
\text { Under load } \\
\left(\mathbf{m m}^{\mathbf{2})}\right.\end{array}$ & $\begin{array}{c}\text { Deflection } \\
\text { curve }\end{array}$ & $\begin{array}{c}\text { Energy } \\
\text { Absorption }\end{array}$ \\
\hline GS 0 & 11.5 & 10 & 1.15 \\
\hline GS 1 & 19 & 7.4 & 2.57 \\
\hline GS 2 & 20 & 7.4 & 2.70 \\
\hline GS 3 & 19.5 & 7.4 & 2.63 \\
\hline
\end{tabular}

Table 3 Ductility Factor

\begin{tabular}{|c|c|c|c|}
\hline Specimen & $\begin{array}{c}\text { Ultimate } \\
\text { Deflection } \\
(\mathbf{m m})\end{array}$ & $\begin{array}{c}\text { Yield } \\
\text { Deflection } \\
\text { (mm) }\end{array}$ & $\begin{array}{c}\text { Ductility } \\
\text { Factor }\end{array}$ \\
\hline GS 0 & 20 & 11 & 1.82 \\
\hline GS 1 & 19.8 & 6.45 & 3.07 \\
\hline GS 2 & 19.4 & 6.35 & 3.06 \\
\hline GS 3 & 19.2 & 6.4 & 3 \\
\hline
\end{tabular}




\subsection{First Crack and Ultimate Load}

First crack load and ultimate load of the specimens are given in Table. First crack load was determined from the envelop curve of the load deflection plot corresponding to the point at which the curve deviated from linearity. From the calculated values it can be observed that first crack load increased with increase in fiber content, which may be due to the increase in tensile strain carrying capacity of concrete in the neighborhood of fibers. The first crack load increased by $18 \%$ for GFRC and $31 \%$ for SFRC specimens. It has been found that addition of hybrid fibres increases first crack load by $37 \%$ and ultimate load by $62 \%$ for HFR0C specimen with $0.75 \%$ $(55.5 \mathrm{~kg} / \mathrm{m} 3)$ steel fibres and $0.33 \%(24.4 \mathrm{~kg} / \mathrm{m} 3)$ glass fibres when compared to specimen without .Energy absorption capacity and displacement ductility The area under the load deflection curve indicates the energy absorption capacity. Energy absorption capacity was calculated and the values obtained are given in Table 2. From the Table it can be seen that energy absorption capacity consistently increases and maximum for HFRC specimen with $0.75 \%(55.5 \mathrm{~kg} / \mathrm{m} 3)$ steel fibres and $0.33 \%(24.4 \mathrm{~kg} / \mathrm{m} 3)$ glass fibres, which is approximately 3 times higher than that of HPC joints. It is required that an earthquake resistant structure should be capable of deforming in a ductile manner when subjected to lateral loads in several cycles in the elastic range. Ductility of a structure is its ability to undergo deformation beyond the initial yield deformation, while still sustaining load. The ductility factor which is a measure of ductility of a structure is defined as the ratio of maximum deflection $\left(\mathrm{d}_{\mathrm{u}}\right)$ to the deflection at yield $\left(\mathrm{d}_{\mathrm{y}}\right)$. The ductility factors were calculated and the results obtained are given in Table. The details of the procedure adopted are described elsewhere [22]. The values in Table 2 and 3 shows that the fibers present in the mixtures influence the energy absorption capacity and ductility. Compared to HPC specimen the ductility factor is increased by 2.5 times.

\section{CONCLUSION}

The main aim of this paper is to determine load deflection characteristics, energy dissipation, ductility and stiffness degradation of hybrid fiber reinforced beam column joints subjected to reverse cyclic loading were investigated.

1) Hybrid mix Fiber shows the increase the first- crack Strength as well as better ductile in nature. Glass Fiber reduces the micro Cracks, where Metallic fiber of steel Reduce the macro cracks.

2) Expecting results of more than 3times the strength of Controlled mix specimen with $0.75 \%$ of steel fiber and $0.33 \%$ of glass fiber mixed with hybrid type in the junction.

3) This study deals possible to reduce the reinforcement in the beam-column joints for construction difficulties.

4) The comparison between the analytical with the experimental values there is no much difference between this deflection and loading values more or less same in both.

\section{ACKNOWLEDGMENTS}

The authors would like to thank to all the members who have contributed towards development and success of this research work.

\section{REFERENCES}

[1] S. Rajagopal, S. Prabavathy (2013),"Investigation on the seismic behavior of exterior beam-column joint using T-type mechanical anchorage with hair-clip bar"1-11,Journal of King Saud University - Engineering Sciences.

[2] N. Ganesan et al(2014)"Behaviour of hybrid fibre reinforced concrete beam-column joints under reverse cyclic loads"686-693, Materials and Design 54

[3] R. Kiran et al(2014), "A case study on pre 1970s constructed concrete exterior beam-column joints" 2025,Case Studies in Structural Engineering 1.

[4] Akanshu Sharma et al(2011),"A new model to simulate joint shear behavior of poorly detailed beam-column connections in RC structures under seismic loads" 10341051, Engineering Structures 33.

[5] Gerson Moacyr Sisniegas Alva et al (2013), "Momentrotation relationship of $\mathrm{RC}$ beam-column connections: Experimental tests and analytical model" 1427-1438, Engineering Structures 56.

[6] Roberto Realfonzo (2014), "Cyclic behavior of RC beamcolumn joints strengthened with FRP systems", 282-297, Construction and Building Materials 54.

[7] C.E. Sofias et al(2014), "Experimental and FEM analysis of reduced beam section moment endplate connections under cyclic loading" 320-329, Engineering Structures 59.

[8] K.R. Bindhu et al(2009), "Performance of Exterior BeamColumn Joints Under Seismic Type Loading" 47-64, ISET Journal of Earthquake Technology, Paper No. 503, Vol. 46, No. 2.

[9] Gustavo J. et al(2005),"Highly Damage-Tolerant BeamColumn Joints Through Use of High-Performance FiberReinforced Cement Composites"487-495, ACI Structural Journal.

[10] S. S. Patil et al(2013), "Analysis of Reinforced BeamColumn Joint Subjected to Monotonic Loading"149158, International Journal of Engineering and Innovative Technology (IJEIT).

[11] Bo Yang et al(2014),"Behavior of Composite BeamColumn Joints in a Middle-Column-Removal Scenario: Experimental Tests”.04013045-1-04013045-20.

[12] Mohamed Mady (2011), "Seismic Behavior of BeamColumn Joints Reinforced with GFRP Bars and Stirrups", Journal of Composites for Construction, 875-886.

[13] S M Kularni (2013), “A Novel Reinforcement Pattern for Exterior Reinforced Concrete Beam-Column Joint" Procedia Engineering 51, $184-193$.

[14] M. Kazem Sharbatdar et al(2012) "Cyclic performance of retrofitted reinforced concrete beam-column joints using steel prop"287-294,Construction and Building Materials 36.

[15] J.G. Ruiz-Pinilla et al(2014),"Experimental tests on retrofitted RC beam-column joints under designed to seismic loads - General approach", 702-714, Engineering Structures, 59.

[16] Gee-Joo Ha (2013), "Seismic improvement of RC beamcolumn joints using hexagonal CFRP bar combined with CFRP sheets"464-470, Composite structures 95 